Віктор Опанасович Муренко (кандидат військових наук, професор) Віталій Миколайович Безуглий

Національний університет оборони Украӥни імені Івана Черняховського, Київ, Украӥна

\title{
ДО ПИТАННЯ ОЦІНЮВАННЯ ЕФЕКТИВНОСТІ ОБ'ЄДНАНОЇ ПІДГОТОВКИ СИЛ ОБОРОНИ ВІЙСЬКОВОЇ ЧАСТИНИ НАДВОДНИХ СИЛ ВІЙСЬКОВО-МОРСЬКИХ СИЛ ТА МОРСЬКОЇ ОХОРОНИ ДЕРЖАВНОї ПРИКОРДОННОї СЛУЖБИ
}

\begin{abstract}
У даній статті на основі системного аналізу практичної діяльності визначено підходи до оиінювання ефективності об'єднаної підготовки військових частинами надводних сил ВійськовоМорських Сил Збройних Сил України та морської охорони Державної прикордонної служби України, складових сектору безпеки і оборони держави. Обтрунтовано вибір основних показників об'єднаної підготовки сил оборони держави, які в свою чергу забезпечать досягнення необхідного рівня взаємодіі військових частин надводних сил Військово-Морських Сил та морської охорони Державної прикордонної служби України, і враховують набуття штабом спроможностей щодо планування спільного виконання завдань та застосування в ході виконання спільних завдань об'єднаними тактичними групами, набуття підрозділами військових частин надводних сил Військово-Морських Сил та морської охорони Державної прикордонної служби України спроможностей спільно діяти в складі об'єднаних корабельних тактичних груп. Визначена система показників максимально розкриває особливості процесу управління та навченості об'єднаною підготовкою сил оборони, які впливатимуть на ступінь досягнення мети об 'єднаної підготовки сил оборони держави, а також вказує на їх структуру та ієрархічність.
\end{abstract}

Ключові слова: об'єднана підготовка сил оборони; надводні сил Військово-Морських Сил; морська охорона Державної прикордонної служби; показники.

\section{Вступ}

Досвід застосування військових формувань сил безпеки i оборони в зоні проведення антитерористичної операції (АТО) свідчить про наявність низки невирішених (проблемних) питань, що значно знижує ефективність виконання ними поставлених завдань. До таких питань, у першу чергу, доцільно віднести недосконалість підготовки штабів та підрозділів військових частин діяти спільно у складі міжвідомчих тактичних груп та угруповань. В той самий час досвід проведення АТО та операції об'єднаних сил (OOC) вказує на зростання ступеню застосування військових частин надводних сил ВійськовоМорських Сил Збройних Сил України (BMC) у складі міжвідомчих угруповань, що в свою чергу вимагає спільного виконання окремих завдань військових частин надводних сил ВійськовоМорських Сил Збройних Сил України (BMC) 3 морською охороною Державної прикордонної служби України (МО ДПС).

Все це вимагає особливої уваги щодо, набуття сумісності визначеним складом сил оборони, підвищенню рівня індивідуальної фахової підготовки особового складу. [6]

Постановка проблеми. В останній період проведення АТО та ООС постала гостро проблема підготовки кваліфікованих військових кадрів органів військового управління (ОВУ), які забезпечать якісне планування бойових дій та управління військами (силами) вході їх ведення. Разом 3 тим в начальний період проведення бойових дій, а також і у подальшому вказує на низький рівень взаємодії сил оборони при спільному виконанні завдань, внаслідок попередніх помилок виправлення яких можливо за рахунок об'єднаної підготовки сил оборони (ОПСО) та набуття спроможностей щодо планування бойових дій міжвідомчих угруповань.

На даний час питання організації об'єднаної підготовки Збройних Сил України та інших складових сил оборони знаходиться на початковому етапі визначення іiі загальних принципів, підходів та визначення загальної структури [4].

Відсутність єдиних поглядів щодо порядку набуття спроможностей спільного виконання завдань у військових частин надводних сил ВМС та МО ДПС, знижує ефективність заходів ОПСО та практично унеможливлює досягнення іï мети [3].

Аналіз останніх досліджень i публікацій. Питанням дослідження ефективності підготовки була присвячена низка попередніх робіт.

Аналіз цих робіт свідчить, що за допомогою різних наукових підходів можливо оцінити результати підготовки військовослужбовця, штабу, підрозділу, отримати комплексну безрозмірну оцінку. Проте, дослідники виходили 3 тих наукових завдань, які були породжені актуальними проблемами практики свого часу, застосовували такі показники i критерії, які найбільш повно відображали процеси, що розглядалися. Водночас зміни, які відбулися у практиці бойової підготовки військових частин свідчать, що їх не достатньо для визначення ефективності системи об'єднаної підготовки сил оборони [5].

Метою статті $€$ запровадження єдиних поглядів на теоретичні положення оцінювання 
ефективності ОПСО, визначити основні показники які впливають на ступінь досягнення мети системи ОПСО, а також їх структуру і ієрархічність.

\section{Виклад основного матеріалу дослідження}

Для оцінювання ефективності ОПСО доцільно визначити критерій, а саме безрозмірну величину $\mathrm{W}_{\mathrm{B}}(\mathrm{t})$, якій привласнимо характеристики готовності військової частини до взаємодії об'єктів підготовки на час t. Визначимо іiї в якості узагальненого показника, за допомогою якого будемо визначати набутий рівень взаємодії військових частин надводних сил ВМС та МO ДПС спільно виконувати завдання у складі об'єднаних корабельних тактичних груп (ОКТГ).

Значення узагальненого показника рівня взаємодії $\mathrm{W}_{\mathrm{B}}(\mathrm{t})$ лежить у межах від 0 до 1:

$$
0<\mathrm{W}_{\mathrm{B}}(\mathrm{t}) \leq 1
$$

Безпосередній вплив на набуття взаємодії здійснюють інтегральні показника, за допомогою яких пропонується оцінювати іiі рівень під час виконання заходів ОПСО. Інтегральними показниками визначаємо "рівень взаємодії військової частини ВМС" та "рівень взаємодії військової частини МО ДПС”, саме вони i визначатимуть рівень взаємодії спільного виконання завдань.

Тоді функціональна залежність матиме наступний вигляд:

$$
\mathrm{W}_{\mathrm{B}}(\mathrm{t})=\mathrm{f}_{\mathrm{B}}\left\{\mathrm{E}_{\text {Ввмс }}(\mathrm{t}) ; \mathrm{E}_{\text {Вмо }}(\mathrm{t})\right\},
$$

де: $\mathrm{E}_{\text {Ввмс }}(\mathrm{t}) ; \mathrm{E}_{\text {Вмо }}(\mathrm{t})$ - інтегральні показники “рівень взаємодії військової частини ВМС”, “рівень взаємодії військової частини МО ДПС” на дискретний момент часу $\mathrm{t}$.

Інтегральні показники залежать від сукупності часткових показників, які розкривають фізичний зміст та визначають відповідний рівень у безрозмірній величині.

Фізичний зміст інтегрального показника "рівень взаємодії військової частини ВМС (MO ДПС)" полягає в тому, що він характеризує спроможність штабу військової частини надводних сил ВМС (MO ДПС) на час $t$ здійснювати планування застосування та управління діями ОКТГ у ході спільного виконання окремих завдань та готовність ОКТГ виконувати завдання задля, яких вона була створена на час $t$.

$$
\mathrm{E}_{\text {Ввмс (мо) }}(\mathrm{t})=\mathrm{f}_{\text {Ввмс (мо })}\left\{\begin{array}{l}
\mathrm{H}_{\text {СПш }}(\mathrm{t}) ; \\
\mathrm{H}_{\text {СПоктг }}(\mathrm{t})
\end{array}\right\},
$$

Спроможність штабу військової частини НС ВMC (MO ДПС) залежить від управлінської діяльності суб'єктів ОПСО, його укомплектованості особовим складом, навченості особового складу і рівня забезпечення підготовки. Тоді функціональна залежність матиме вигляд:

$$
\mathrm{H}_{\text {СПш }}(\mathrm{t})=\mathrm{f}_{\mathrm{C \Pi ш}}\left\{\begin{array}{l}
\mathrm{H}_{\mathrm{YC \Pi ш}}(\mathrm{t}) ; \mathrm{H}_{\mathrm{y}_{ш}}(\mathrm{t}) ; \\
\mathrm{H}_{\mathrm{Hш}}(\mathrm{t}) ; \mathrm{H}_{\mathrm{P} 3 ш}(\mathrm{t})
\end{array}\right\},
$$

де: $\mathrm{H}_{\text {усП }}(\mathrm{t}) ; \mathrm{H}_{\mathrm{y}_{ш}}(\mathrm{t}) ; \mathrm{H}_{\mathrm{Hш}}(\mathrm{t}) ; \mathrm{H}_{\mathrm{P} 3 ш}(\mathrm{t})$ - часткові показники “управління ОПСО штабу”, “укомплектованість штабу особовим складом", “навченість штабу” та "рівня забезпечення ОПСО” на дискретний момент часу $\mathrm{t}$.

Будемо рахувати, що штаб військової частини надводних сил ВМС (МО ДПС) під час процесу навчання укомплектовані особовим складом на $100 \%$, а рівень забезпечення дозволяє виконати всі заходи, які заплановані суб'єктом підготовки на OПСО, тому частковий показники $\mathrm{H}_{\mathrm{y}_{ш}}(\mathrm{t}) ; \mathrm{H}_{\text {РЗш }}(\mathrm{t}) ;$ приймаємо рівним одиниці, тоді вираз (4) можна записати у такому вигляді:

$$
\mathrm{H}_{\mathrm{C} \Pi ш}(\mathrm{t})=\mathrm{f}_{\mathrm{C \Pi ш}}\left\{\mathrm{H}_{\text {УСПш }}(\mathrm{t}) ; \mathrm{H}_{\mathrm{Hш}}(\mathrm{t})\right\} \text {, }
$$

Фізичний зміст часткового показника “готовність ОКТГ” $\mathrm{K}_{\text {СПоктг }}(\mathrm{t})$ полягає в тому, що він характеризує спроможність ОКТГ виконати завдання за призначенням. Його пропонується розраховувати за функціональною залежністю, яка враховує готовність ОКТГ виконати завдання за призначенням.

Рівень готовності ОКТГ залежить від управління діяльності суб'єкта підготовки ОПСО, ii укомплектованості, навченості i рівня забезпечення підготовки. Тоді функціональна залежність матиме наступний вигляд:

$$
\begin{aligned}
& \mathrm{H}_{\text {СПоктг }}(\mathrm{t})=\mathrm{f}_{\text {СПоктг }}\left\{\begin{array}{l}
\mathrm{H}_{\text {УСПоктг }}(\mathrm{t}) ; \\
\mathrm{H}_{\text {УоктГ }}(\mathrm{t}) ; \\
\mathrm{H}_{\text {НоктГ }}(\mathrm{t}) ; \mathrm{H}_{\mathrm{P} 3}(\mathrm{t})
\end{array}\right\}, \\
& \text { де: } \quad \mathrm{H}_{\text {УСоктГ }}(\mathrm{t}) ; \mathrm{H}_{\text {УоктГ }}(\mathrm{t}) ; \mathrm{H}_{\text {Ноктг }}(\mathrm{t}) ; \mathrm{H}_{\mathrm{P} 3}(\mathrm{t})
\end{aligned}
$$
часткові показники “управління ОПСО ОКТГ”, “укомплектованість ОКТГ”, “навченість ОКТГ” та “рівня забезпечення ОПСО ОКТГ" на дискретний момент часу $\mathrm{t}$.

Будемо рахувати, що ОКТГ підчас процесу навчання укомплектовані особовим складом на $100 \%$, а рівень забезпечення дозволяє виконати всі заходи які заплановані суб'єктом підготовки на ОПСО тому частковий показники $\mathrm{H}_{\text {Уоктг }}(\mathrm{t}) ; \mathrm{H}_{\mathrm{P3}}(\mathrm{t}) ;$ приймаємо рівним одиниці, тоді вираз (6) можна записати у такому вигляді:

$$
\mathrm{H}_{\text {СПоктг }}(\mathrm{t})=\mathrm{f}_{\text {СПоктг }}\left\{\begin{array}{l}
\mathrm{H}_{\text {УСПоктГ }}(\mathrm{t}) ; \\
\mathrm{H}_{\text {Ноктг }}(\mathrm{t}) ;
\end{array}\right\},
$$

Для оцінювання управління ОПСО суб'єктами підготовки, навченості об'єктів ОПСО пропонується використовувати часткові показники.

Частковий показник “управління ОПСО штабу $\mathrm{H}_{\text {усПш }}(\mathrm{t})$ " залежить від повноти i якості планування ОПСО штабу (ОКТГ), організаційної структури i формування в ній управлінської ієрархії ОПСО штабу (ОКТГ), сукупність спонукальних стимулів суб'єктів підготовки та своєчасному виявленні відхилень у підготовці суб'єктами підготовки ОПСО штабу (ОКТГ). Тоді функціональна залежність матиме вигляд:

$$
\begin{aligned}
& \mathrm{H}_{\text {усПш }}(\mathrm{t})=\mathrm{f}_{\text {УСПш }}\left\{\begin{array}{l}
\mathrm{M}_{\Pi C \Pi}(\mathrm{t}) ; \mathrm{M}_{\text {Орг }}(\mathrm{t}) ; \\
\mathrm{M}_{\mathrm{MC \Pi}}(\mathrm{t}) ; \mathrm{M}_{\mathrm{KC \Pi}}(\mathrm{t})
\end{array}\right\}, \\
& \mathrm{H}_{\text {уСПоктг }}(\mathrm{t})=\mathrm{f}_{\text {УСПоктा }}\left\{\begin{array}{l}
\mathrm{M}_{\text {ПСп }}(\mathrm{t}) ; \\
\mathrm{M}_{\mathrm{OpгC}}(\mathrm{t}) ; \\
\mathrm{M}_{\mathrm{MCn}}(\mathrm{t}) ; \\
\mathrm{M}_{\mathrm{KC \Pi}}(\mathrm{t})
\end{array}\right\} \text {, }
\end{aligned}
$$


де: $\quad \mathrm{M}_{\Pi \text { пп }}(\mathrm{t}), \mathrm{M}_{\text {Орг пп }}(\mathrm{t}), \mathrm{M}_{\text {мсп }}(\mathrm{t}), \mathrm{M}_{\text {Ксп }}(\mathrm{t}) \quad$ показники, які характеризують “планування СПСО штабу (ОКТГ)”, “організацію СПСО штабу (ОКТГ)", “мотивацію ОПСО штабу (ОКТГ)” та “контроль ОПСО штабу (ОКТГ)".

Частковий показник “навченість штабу НC ВMC (MO ДПС) $\mathrm{H}_{\mathrm{Hш}}(\mathrm{t})$ (ОКТГ) $\left.\mathrm{H}_{\text {Ноктг }}(\mathrm{t})\right)$ ” залежить від сукупного рівня індивідуальних спроможностей кожного флагманського спеціаліста штабу (командира корабля) та взаємодії флагманських фахівців штабу (злагодженості ОКТГ). Тоді функціональна залежність матиме наступний вигляд:

$$
\mathrm{H}_{\mathrm{H \omega}}(\mathrm{t})=\mathrm{f}_{\mathrm{H} \omega}\left\{\mathrm{C}_{\mathrm{IC} \omega}(\mathrm{t}) ; \mathrm{C}_{\mathrm{B \phi}}(\mathrm{t})\right\},
$$

де: $\mathrm{C}_{\mathrm{IC}}(\mathrm{t}) ; \mathrm{C}_{\mathrm{B \phi}}(\mathrm{t})$ - показники “сукупний рівень індивідуальних спроможностей флагманського

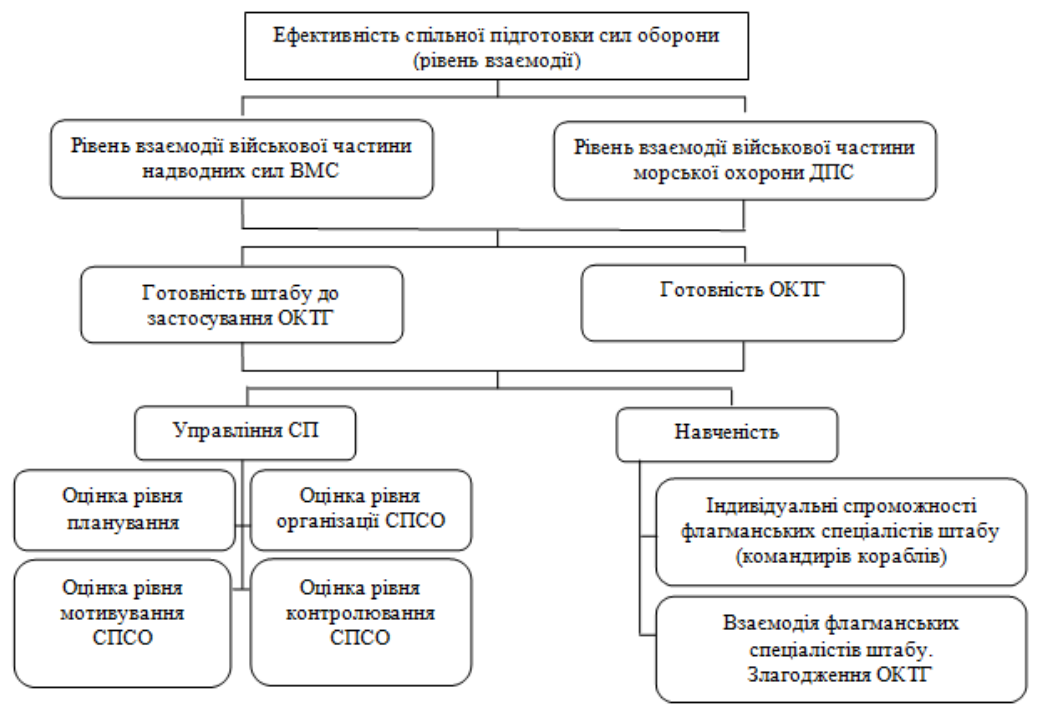

Рис. 1. Система показників оцінювання ефективності об'єднаної підготовки сил оборони військової частини надводних сил ВМС та морської охорони ДПС
Метод згортки показників дозволяе звести багатокритеріальну задачу до однокритеріальної, а вище зазначені показники усіх рівнів будуть мати різну вагомість. Тому під час їх згортки будуть застосовані відповідні "вагові" коефіцієнти, які розрахуємо методом експертного оцінювання.

Зважаючи на те, що інтегральні показники сильно корельовані, для визначення узагальненого показника $\mathrm{W}_{\mathrm{B}}(\mathrm{t})$ пропонується використовувати нормовану мультиплікативну агрегацію [2]:

$$
\mathrm{W}_{\mathrm{B}}(\mathrm{t})=\mathrm{E}_{\text {Ввмс }}(\mathrm{t}) \mathrm{q}_{\text {вмс }} \cdot \mathrm{E}_{\text {Вмо }}(\mathrm{t}) \mathrm{q}_{\text {мо }}
$$

де: $\mathrm{E}_{\text {Ввмс }}(\mathrm{t})$ - значення інтегрального показника "рівень взаємодії військової частини ВМС" на час $t$;

$\mathrm{E}_{\text {Вмо }}(\mathrm{t})$ - значення інтегрального показника “рівень взаємодії військової частини МО ДПС” на час $\mathrm{t}$;

$\mathrm{q}_{\text {вмс; }} \mathrm{q}_{\text {мо }}$ - вагові коефіцієнти інтегральних показників. спеціаліста штабу”, взаємодія флагманських фахівців штабу";

$$
\mathrm{H}_{\text {НоктГ }}(\mathrm{t})=\mathrm{f}_{\text {Ноктг }}\left\{\begin{array}{c}
\mathrm{C}_{\text {ІСкк }}(\mathrm{t}) ; \\
\mathrm{C}_{\text {ЗоктГ }}(\mathrm{t})
\end{array}\right\} \text {, }
$$

де: $\mathrm{C}_{\text {IСкк }}(\mathrm{t}) ; \mathrm{C}_{\text {Зоктг }}(\mathrm{t})$ - показники “сукупний рівень індивідуальних спроможностей командирів кораблів ОКТГ”, злагодження ОКТГ”.

Система показників, яка використовується для оцінювання ефективності ОПСО наведена на рисунку 1.

\section{Висновки й перспективи подалыших досліджень}

Таким чином, зрозумілим $є$ те, що об'єднана підготовки сил оборони покликана вирішити основні питання щодо набуття взаємодії військових формувань і правоохоронних органів, підвищити ефективність виконання бойових та спеціальних завдань в ході спільних дій.

Метою ОПСО буде інтеграція спроможностей 3С та інших складових сил оборони задля виконання певних завдань за певних умов, ресурсного забезпечення та відповідно до встановлених стандартів.

В подальших дослідженнях слід звернути увагу на:

розвиток системи показників об'єднаної підготовки сил оборони;

удосконалення комплексної методики оцінювання ефективності підготовки сил оборони.

Трансформацію існуючих форм (способів) підготовки військ (сил);

пошук нових нестандартних варіантів бойового навчання, які спроможні максимально реалізувати бойовий потенціал військових частин. 


\begin{abstract}
Jimepamypa
1. Брахман T.P. Многокритериальность и выбор альтернатив в технике / Т.Р. Брахман - М. : Радио, 1984. - 364 с. 2. Вентцель Е.С. Исследование операций / Е.С. Вентцель. - М. : “Советское радио”, 1972. - 552 с. 3. Сдиний перелік (каталог) спроможностей Міністерства оборони України та Збройних Сил України: за станом на 28 лис. 2017 р. - К. : МОУ, 2017. 27 с. (Нормативний документ Міністерства оборони України та Генерального штабу Збройних Сил України.) 4. Концепція підготовки Збройних Сил України : за

станом на 22 лют. 2016 р. - К. : Мін-во оборони України та ГШ ЗСУ, 2016. - 14 с 5. Хома В.В. Вимоги до спільної підготовки і застосування збройних сил та державної прикордонної служби України: Збірник тез доповідей Міжнародної науково-практичної конференції "Інтегроване управління кордоном. Теорія і практика". 2013. - 130 с. 6. Указ Президента України №240/2016 "Про рішення Ради національної безпеки і оборони України від 20 травня 2016 року "Про Стратегічний оборонний бюлетень України”.
\end{abstract}

\title{
В ВОПРОСУ ОЦЕНКИ ЭФФЕКТИВНОСТИ ОБЪЕДИНЕННОЙ ПОДГОТОВКИ СИЛ ОБОРОНЫ ВОИНСКОЙ ЧАСТИ НАДВОДНЫХ СИЛ ВОЕННО-МОРСКИХ СИЛ И МОРСКОЙ ОХРАНЫ ГОСУДАРСТВЕННОЙ ПОГРАНИЧНОЙ СЛУЖБЫ
}

Виктор Панасович Муренко (кандидат военных наук, профессор) Виталий Николаэвич Безуглий

\section{Национальный университет обороны Украины имени Ивана Черняховского, Киев, Украина}

В данной статье, на основе системного анализа практической деятельности определены подходы $к$ оченке эффективности совместной подготовки воинских частей надводных сил Вооруженных Сил Украины и морской охраны Государственной пограничной службы Украины, составных частей сектора безопасности и обороны государства. Обоснован выбор наиболее влиятельных показателей совместной подготовки сил обороны государства, что в свою очередь обеспечат достижение необходимого уровня взаимодействия воинских частей надводных сил ВоенноМорских Сил и морской охрань Государственной пограничной службы Украины, и учитывают приобретение штабом возможностей по планированию совместного выполнения задач и применения 6 ходе выполнения общих задач объединенными тактическими группами, приобретение подразделениями вочнских частей надводных сил Военно-Морских Сил и морской охрани Государственной пограничной службы возможностей совместно действовать в составе объединенных корабельных тактических групп. Определенная система показателей максимально раскрывает особенности процесса управления и обучения общей подготовкой сил обороны, которые будут влиять на степень достижения цели совместной подготовки сил обороны государства, а также указывает на их структуру и иерархичность.

Ключевые слова: объединенная подготовка сил обороны; надводные сил Военно-Морских Сил; морская охрана Государственной пограничной службы; показатели.

\section{ON THE ISSUE OF EVALUATING THE EFFECTIVENESS OF JOINT TRAINING OF THE DEFENSE FORCES OF THE MILITARY PART OF THE SURFACE FORCES OF THE NAVAL FORCES AND THE MARITIME SECURITY OF THE STATE BORDER GUARD SERVICE}

Viktor Murenko (Candidate of military sciences, Professor) Vitalii Bezuhlyi

\section{National Defence University of Ukraine named after Ivan Cherniakhovsky, Kyiv, Ukraine}

In this article, based on a systematic analysis of practical activities, approaches to assessing the effectiveness of joint training of military units of the Armed Forces of Ukraine and maritime security of the State Border Service of Ukraine, constituent parts of the security and defense sector of the state are determined. The choice of the most influential indicators of joint training of the State Defense Forces is substantiated, which in turn will ensure the achievement of the necessary level of interaction between the military units of the Naval Forces and the Maritime Protection of the State Border Service of Ukraine, and take into account the acquisition by the staff of opportunities for planning joint execution of tasks and application fulfillment of common tasks by joint tactical groups, acquisition by units of military units of surface forces of the Navy of the State Border Guard Service of the State Opportunity to act jointly within the Joint Tactical Groups. The system of indicators as much as possible reveals the peculiarities of the process of management and training of the general training of the defense forces, which will influence the degree of achievement of the goal of joint training of the defense forces of the state, as well as indicate their structure and hierarchy.

Key words: joint training of the Defense Forces; surface warfare forces of the Navy; coast guard State Border Service.

\section{References}

1. Brahman T.R. Multicriteria and the choice of alternatives in engineering. Brahman - M.: Radio, 1984. 364 p. 2. Wentzel ES Operations research / ES Wentzel. M.: "Soviet Radio", 1972. - 552 p. 3. Single list (catalog) of the capabilities of the Ministry of Defense of Ukraine and the Armed Forces of Ukraine: as of 28 November. 2017 K.: MOU, 2017. - 27 p. 4. The concept of training of the Armed Forces of Ukraine: as of February 22. 2016 - K.: Ministry of Defense of Ukraine and the General Staff of the
Armed Forces of Ukraine, 2016. - 14 p. 5. Homa VV Requirements for Joint Training and Use of the Armed Forces and the State Border Guard Service of Ukraine: Proceedings of the International Scientific Conference on Integrated Border Management. Theory and Practice". 2013. - 130 p. 6. Presidential Decree No. 240/2016 "On the Decision of the National Security and Defense Council of Ukraine of May 20, 2016“ On the Strategic Defense Bulletin of Ukraine ". 